\title{
STATISTICAL AND COST EFFICIENCY OF SIMPLE RANDOM SAMPLING AND SYSTEMATIC SAMPLING IN ESTIMATING FOREST STAND PARAMETERS AT YAGIRALA
}

\author{
M C Karunaratne ${ }^{1}$ and T I Mohammed ${ }^{2}$ \\ 1 University of Sri Jayewardenepura \\ 2 State Timber Co-operation.
}

The study was carried out at a 24 years old Pinus carloced plantation located in lowland wet zone of Sri Linka. Statistical and cost efficiency were compared at sampling intensities of $11.1 \% .19 .4 \%$ and $32.4 \%$, using simple random sampling design and systematic sampling design. Circular sampling units of 0.05 ha with slope correction, and boundary adjustment were also applied. Sampling units of simple random sampling were arranged in a hexagonal pattern, and selected (without replacement) after generating random numbers. Diameter al breast height and total height within each sampling unit were measured to estimate hasal area per ha and volume per ha. Walking time and measuring time were recorded to calculate the variable costs of the inventory of all species at $32.4 \%$ sampling intensity.

The pine population shows normal distribution, and simple random sampling represents it more closely than systematic sampling. Naturally regenerated tree species under pine plantation are effecting the diameter distribution.

Simple random sampling gives better estimates of basal area per ha and volume per ha for pine than systematic sampling. For all species, systematic sampling gives better estimates all lower sampling intensities.

In simple random sampling, the most efficient sampling intensity is $32.4 \%$. However. $11.1 \%$ can be recommended for $25 \%$ sampling error. In all species, relative efficiency of the two sampling designs does not show a significant difference. Simple random sampling is more efficient lor all species at $32.4 \%$ intensity.

The delayed silvicultural operation is found to effect the pine population and there is a need for proper management of the forest.

Procededings of the Fourth Ammal Forestry and Environment Symposium 1998 of the Depertme'nt of Forestry and Envirommental Scionce. University of Sri Jayenardenepura. Sri Lanka 